\title{
TOLERANCIA, AUTONOMÍA E INMORALIDADES "INOFENSIVAS" O "SIN VÍCTIMAS"
}

\author{
JuAn Pablo Zambrano Tiznado \\ Escuela de Derecho \\ Universidad Arturo Prat, Chile \\ juanpablo.zambranotiznado@gmail.com
}

RESUMEN: Este trabajo tiene como objetivo argumentar a favor de la tolerancia de ciertas "inmoralidades inofensivas o sin víctimas". Tomando como punto de partida el liberalismo perfeccionista de Joseph Raz, así como la crítica que de él hace Robert P. George, se plantean argumentos a favor de tolerar ciertos males en aras de evitar que se instrumentalice a las personas. Como conclusión se afirma que, aunque equivocadamente, es posible elegir realizar acciones consentidas que atenten contra el principio del daño.

PALABRAS CLAVE: principio del daño, agente moral, instrumentalización de las personas, Joseph Raz, Robert P. George

SUMMARY: This paper argues for tolerance of some "harmless or victimless immoralities". To this end - and taking into account both Joseph Raz's perfectionist liberalism, and the critique of the latter by Robert P. George - arguments are set forth for tolerance of some evils aimed at avoiding using people as a means. In conclusion, it is stated that, although mistakenly, people should be free to carry out consented actions which infringe upon harm principle.

KEY WORDS: harm principle, moral agent, use of people, Joseph Raz, Robert P. George

\section{Introducción}

En este trabajo se argumenta a favor de la tolerancia de ciertos males. Ya han emprendido esta misma tarea distintos filósofos morales - especialmente los liberales antiperfeccionistas —, quienes se han centrado en el clásico principio del daño que formuló John Stuart Mill. También Joseph Raz se ha dedicado a esta tarea adoptando el enfoque del liberalismo perfeccionista.

La propuesta raziana es seductora porque argumenta a partir de un concepto amplio de daño y a partir de un principio de tolerancia basado en la autonomía. ${ }^{l}$ No obstante, como ha mostrado Robert P. George, uno de los argumentos de Raz que sirve para justificar la

${ }^{1}$ El argumento de Raz alude a la autonomía personal y no a la autonomía moral. En el caso de la autonomía moral "el principio de autonomía implica que se actúe en base al propio juicio en todas las cuestiones morales" (Raz 1985, pp. 17-18). En cambio, la autonomía personal tiene que ver con que cada persona es autora, en parte, de su propia vida al orientarla mediante decisiones sucesivas (Raz 1999, p. 93). En este trabajo cuando hable de autonomía me estaré refiriendo a la autonomía personal. 
tolerancia de ciertas "inmoralidades inofensivas o sin víctimas" fracasa. Por ello, en este trabajo, siguiendo el liberalismo perfeccionista de Raz, trataré de plantear un argumento que sea inmune a la crítica del profesor George.

\section{Las inmoralidades inofensivas o sin víctimas}

La tolerancia, tal como la defiende Raz, tiene por fundamento la autonomía y, por límite, el principio del daño (1999). Sin embargo, Raz modifica conceptualmente este principio de modo que extiende lo no tolerable más allá de los límites tradicionalmente defendidos por el liberalismo. Ahora, el "principio del daño" [harm principle] incluye aquellas acciones, omisiones, injurias u ofensas que dejan al agente o a un tercero peor de lo que debería estar ( $\operatorname{Raz} 1999$, pp. 106108). Así, según la argumentación de Raz, la autonomía sólo sirve para fundamentar la tolerancia de bienes (1999, p. 98, p. 106; 1986a, p. 381), y entonces los males exceden el límite de lo tolerable al violar el principio del daño. En este punto de la argumentación, Raz tiene que admitir que la autonomía no provee razones para tolerar" "inmoralidades inofensivas o sin víctimas" como la prostitución; ${ }^{3}$ pero para defender que se toleren este tipo de males afirma que la coacción atenta contra la autonomía y, por lo tanto, se deberían "tolerar" este tipo de inmoralidades (1986a, pp. 418-419). Para sostener su afirmación Raz presenta dos argumentos. No obstante, me parece que independientemente de que los aceptemos, Raz olvida que al sostener que debemos tolerar las "inmoralidades inofensivas o sin víctimas" la autonomía personal ya no ofrece razones para tolerar. En efecto, utilizar la expresión "tolerar" en estos casos es una impropiedad, ya que al extender el concepto de "principio del daño" Raz debe admitir que estas conductas dañan a quienes las practican y no constituyen un ejercicio valioso de la autonomía personal. Por lo tanto, la prostitución y la pornografía no deben formar parte de la gama adecuada de opciones que el Estado debe tolerar (Raz 1999, p. 110). Sin embargo, como dije anteriormente, según Raz se puede reprimir la indignación frente a la prostitución, y por lo tanto modificar el

${ }^{2}$ Según Raz (1999, p. 100) también se deben tolerar ciertas limitaciones en la medida en que ellas son el costo del desarrollo de alguna virtud. Sin embargo, éste no es el caso de las inmoralidades inofensivas o sin víctimas.

${ }^{3}$ Para Raz (1986a, p. 162) la prostitución debilitaría la concepción monogámica del matrimonio. Robert P. George, quien argumenta a favor de la concepción tradicional del matrimonio, afirma que "[l]a normatividad de este tipo de comunidad surge del hecho de que es un bien básico e irreductible, perfectivo de los seres humanos" (2009, p. 205). 
estatus deóntico de la práctica, no porque ella represente una opción digna de ser elegida, sino porque considera que "las interferencias coactivas" (1986a, pp. 418-419; 1999, p. 111) violan la autonomía. Con todo, los argumentos de Raz no extienden la tolerancia a lo malo o lo repugnante porque él considere valioso elegir el mal, sino porque considera que la coacción es repugnante ya que atenta contra la autonomía personal al violar el principio del daño (1986a, p. 403; 1999, p. 111). Conforme al primer argumento de Raz (1986a, pp. 418$419 ; 1999$, p. 111), la coacción viola la autonomía porque tiene un carácter global e indiscriminado. Esto quiere decir que el ejercicio de la coacción impide al agente tomar una gran cantidad de decisiones sobre su vida, lo que en la práctica implica que pierda su autonomía personal. El segundo argumento afirma que la coacción "viola la condición de independencia y expresa una relación de dominación y una actitud de falta de respeto por el individuo coaccionado" (1986a, pp. 418-419). George, una vez que muestra la inconsistencia de este último argumento, replica de manera contundente que Raz no logra justificar por qué la coacción en las leyes morales viola la autonomía y en las demás leyes penales no lo hace $(2002$, p. 167).

\section{Primer contraargumento: razonabilidad del castigo justo}

Para George (2002, p. 170), la coacción no tiene un carácter global e indiscriminado; además, él sostiene que el bien del castigo justo requiere la limitación de la libertad durante cierto periodo. George está en lo correcto, pues parece razonable que el castigo justo implique cierta pérdida de libertad y Raz parece estar de acuerdo con esto (George 2002, p. 168). Nadie objeta que, por ejemplo, en males como el homicidio — que atenta contra lo justo natural - la gravedad del bien lesionado justifica la imposición de la pena y la limitación de la libertad. En estos casos, podríamos incluso estar de acuerdo en que se afecte gran parte de la autonomía del condenado, y ese daño "colateral" está justificado por el bien del castigo justo. Sin embargo, lo importante respecto de la autonomía personal es que el agente coaccionado tenga una gama adecuada de opciones disponibles, y en la prisión no hay forma de impedir el ejercicio de la conducta dañosa sin, al mismo tiempo, impedir una gran cantidad de opciones valiosas que el sujeto quisiera elegir y que no puede (Raz 1999, p. 111). En ese sentido la coacción es global e indiscriminada.

Ahora bien, respecto del castigo justo, George lo da por hecho en el caso de las inmoralidades inofensivas o sin víctimas. Pero, en contra de lo que George cree (2002, p. 169), no basta como criterio para 
justificar la bondad de la coacción que la norma haya sido sancionada por el legislador para fines legítimos y que el agente incumpla la restricción impuesta a su libertad. ${ }^{4}$ Lo que Raz discute es más bien si resulta correcto que el legislador en la etapa de deliberación ${ }^{5}$ juzgue más justa una "consideración positiva autoritativa" que utilice la coacción como castigo a este tipo de males, y entonces, si aun cuando aceptemos que en el homicidio dicha violación indiscriminada está justificada, George no se ocupa de examinar si es razonable que ocurra lo mismo en el caso de las inmoralidades inofensivas o sin víctimas.

\section{Segundo contraargumento: las leyes morales versus las demás leyes penales}

Asumiendo que el principio del daño incluye no sólo a terceros sino también al propio agente, Raz debe admitir que el Estado tiene que tolerar algunas acciones moralmente malas aunque atenten contra este principio (Raz 1986a, pp. 403 y ss.). Sin embargo, según George (2002, p. 167), Raz no logra "explicar por qué la dimensión coactiva de las leyes de la moral viola ilegítimamente la autonomía, mientras que la dimensión coactiva de otras leyes penales no lo hace". ${ }^{6}$

Mi tesis sostiene que lo que justifica la diferencia entre las leyes de la moral y las leyes penales es que las primeras instrumentalizan a las personas, y las segundas no lo hacen. Si estoy en lo correcto, y de algún modo la autonomía como razón para tolerar se relaciona con el hecho de que se considere a las personas como fines, se puede argumentar a favor de tolerar acciones que atentan contra lo bueno natural pero que son autorreferentes, o que, aun cuando atentan contra lo justo natural, el daño que generan es aceptado por todos los involucrados.

${ }^{4}$ Raz (2001, p. 350; 2001, nota 39l) afirma que el juez siempre tiene discrecionalidad; la tiene incluso para apartarse del derecho y, por lo tanto, para modificar la sanción "al considerar todos los factores en cuenta". Sin embargo, al hacerlo, no dará razones propiamente jurídicas (1986b, p. 256).

${ }^{5} \mathrm{El}$ aspecto moral de la pregunta por la justicia de la acción (i.e., de la decisión de sancionar coactivamente las inmoralidades inofensivas o sin víctimas) pertenece al estadio deliberativo. Cuando la identificación de la razón que funda la decisión se realiza sin acudir a argumentos morales, por estimar que una determinada norma jurídica es una consideración positiva autoritativa, se está en el estadio ejecutivo, lo que implica que los órganos primarios la juzgan autoritativamente establecida (Raz 1986b, pp. 254-256).

${ }^{6}$ Respecto del uso del principio del daño George (2002, p. 167) agrega: "Citar simplemente el principio del daño no será suficiente, porque es éste el principio que Raz está intentando justificar cuando critica el aspecto coactivo de las leyes de la moral." 
Las normas penales son parte de las funciones del derecho, y cumplen una de las funciones primarias: prevenir comportamientos indeseables y propiciar comportamientos deseables (Raz 1985, p. 213). Ahora bien, las normas penales prohíben causar daño a terceros, de modo que la norma actúa como razón excluyente para quien desea obedecer el derecho (Raz 1990, pp. 219 y ss.). En ese sentido, la norma penal cumple una función de prevención general sin afectar ilegítimamente la autonomía. En el caso de la dimensión coactiva de las leyes penales se debe hacer la siguiente precisión. En las leyes de la moral a través de la coacción el Estado sólo logra promover conductas en los ciudadanos, ${ }^{7}$ mientras que en el caso de las demás leyes penales la coacción es, además, una sanción por un daño efectivo realizado a un tercero.

Como afirma Raz (1986a, pp. 418-419; 1999, p. 111), el ejercicio de la coacción implica un atentado a la autonomía personal porque afecta indiscriminadamente casi todas las áreas de decisión del agente. Dicho daño sólo se justifica como respuesta social a un "comportamiento indeseable" (Raz 1985, p. 213). Así, el ejercicio de la coacción es un medio para restablecer el derecho respecto de aquellos ciudadanos que no se ven persuadidos por la razonabilidad de la norma (Raz 1985, pp. 305-306). Esto implica que violar la autonomía personal sólo se justifica cuando la función de la coacción es sancionar un daño determinado realizado a un tercero. De este modo, no se instrumentaliza al agente ya que la prevención general no justifica la coacción; sólo es un complemento de ella.

En mi argumento, elegir el mal siempre carece de valor (de modo que si asumimos que la prostitución es un mal, nunca se debería elegir). Un problema diferente es preguntarse por el valor de ejercer la coacción respecto de quienes han elegido realizar un mal moral que no causa daño a terceros. Sostengo que las "inmoralidades inofensivas o sin víctimas" se deben tolerar porque la coacción en estos casos instrumentaliza a quienes la ejercen. No habiendo causado daño a un tercero el único fin de la coacción es promover en los ciudadanos determinadas conductas. Usar la coacción sólo para promover ciertas conductas es instrumentalizar a quienes autónomamente han elegido realizar un mal que no causa daño a otros.

${ }^{7}$ No se puede sostener en estos casos que la coacción pretenda corregir el "orden social", pues dicho orden no se vio afectado por un daño que sólo sufrió el agente. Tampoco se puede pensar que se coacciona en estos casos para evitar futuros daños que "quizá" el agente se haga a sí mismo. En este caso, bastaría prohibirle que realice la actividad dañosa o simplemente multarlo. 


\section{Conclusión}

La autonomía supone una variedad de opciones valiosas aunque incompatibles, de modo que no sirve como fundamento para defender las "inmoralidades inofensivas o sin víctimas". El costo de extender el principio del daño es que en el caso de ese tipo de inmoralidades ya no se debe propiamente tolerar. En el programa liberal de Raz, la bondad moral de la autonomía personal está dada por la posibilidad de ser constructores — parciales - de la propia vida, lo cual supone tolerar acciones que impliquen renunciar al principio del daño para evitar instrumentalizar a las personas. Es tarea del Estado crear las condiciones de posibilidad para que la elección de bienes incompatibles sea posible. Lo anterior implica suponer que cualquier defensa de la tolerancia basada en la autonomía requiere defender a la persona como fin en sí misma, incluso cuando el agente decida construir equivocadamente su propia vida. ${ }^{8}$

\section{BIBLIOGRAFÍA}

George, Robert P., 2009, Moral pública. Debates actuales, trad. Miriam Rabinovich, Instituto de Estudios de la Sociedad, Santiago, Chile.

- 2002, Para hacer mejores a los hombres. Libertades civiles y moralidad pública, trad. Carmen Ruiz, Ediciones Internacionales Universitarias, Madrid.

Raz, Joseph, 2001, La ética en el ámbito público, trad. María Luz Melon, Gedisa, Madrid.

—_ 1999, "Autonomía, tolerancia y el principio del daño", Revista de Estudios Públicos, no. 76, pp. 91-113.

—_, 1990, Razón práctica y normas, trad. Juan Ruiz Manero, Centro de Estudios Constitucionales, Madrid.

—_ 1986a, The Morality of Freedom, Clarendon Press, Oxford.

- $1986 \mathrm{~b}$, El concepto de sistema jurídico. Una introducción a la teoría del sistema jurídico, trad. Rolando Tamayo y Salmorán, UNAM, México.

_ 1985, La autoridad del derecho. Ensayos sobre derecho y moral, trad. Rolando Tamayo y Salmorán, UnAm, México.

Recibido el 16 de abril de 2010; revisado el 20 de diciembre de 2010; aceptado el 20 de mayo de 2011.

\footnotetext{
${ }^{8}$ Agradezco al doctor Joaquín García-Huidobro sus comentarios pese a que no comparte la tesis que sostengo.
} 